Journal of Applied Pharmaceutical Science Vol. 5 (10), pp. 016-021, October, 2015

Available online at http://www.japsonline.com

DOI: $10.7324 / \mathrm{JAPS} .2015 .501004$

ISSN 2231-3354 (cc) BY-NC-SA

\title{
Ruta graveolens and its active constituent rutin protect against diethylnitrosamine-induced nephrotoxicity through modulation of oxidative stress
}

\author{
Ayman M. Mahmoud ${ }^{1 *}$, Rasha R. Ahmed ${ }^{2}$, Hanan A. Soliman ${ }^{3}$, Marwa Salah $^{3}$ \\ ${ }^{1}$ Physiology Division, Zoology Department, Faculty of Science, Beni-Suef University, Beni-Suef, Egypt. \\ ${ }^{2}$ Cell Biology and Histology Division, Zoology Department, Faculty of Science, Beni-Suef University, Beni-Suef, Egypt. \\ ${ }^{3}$ Biochemistry Division, Chemistry Department, Faculty of Science, Beni-Suef University, Beni-Suef, Egypt.
}

\section{ARTICLE INFO \\ Article history: \\ Received on: 21/07/2015 \\ Revised on: 04/08/2015 \\ Accepted on: 29/08/2015 \\ Available online: 28/10/2015}

Key words:

Rue, Flavonoids, Renal

injury, Oxidative stress,

Antioxidants.

\begin{abstract}
The current study was designed to evaluate the possible protective effects of Ruta graveolens (Rue) and its active phenolic constituent rutin against diethylnitrosamine (DEN)-induced nephrotoxicity in rats. A single dose of DEN $(200 \mathrm{mg} / \mathrm{kg}$ body weight) was intraperitoneally injected. Two-weeks after DEN administration, rats received $0.05 \%$ phenobarbital in drinking water for 12 weeks. Ruta graveolens $(50 \mathrm{mg} / \mathrm{kg})$ and rutin $(50 \mathrm{mg} / \mathrm{kg})$ were orally administered from the first day of experiment. DEN administration induced kidney injury evidenced by histological alterations as well as significant increase in serum urea $(\mathrm{P}<0.01)$, creatinine $(\mathrm{P}<0.001)$ and uric acid $(\mathrm{P}<0.001)$, and renal lipid peroxidation levels. On the other hand, renal glutathione content and activity of superoxide dismutase, glutathione peroxidase and glutathione-s-transferase were significantly declined. Concomitant supplementation with either $R$. graveolens extract or rutin markedly alleviated the altered biochemical and histopathological features. In conclusion, the current findings provide evidence that $R$. graveolens and its active phenolic component rutin could protect against DEN-induced renal damage through abolishment of oxidative stress and potentiation of the antioxidant defense system.
\end{abstract}

\section{INTRODUCTION}

Drug-induced nephrotoxicity is a serious kidney problem and is responsible for a variety of pathological effects on the kidneys (Sarang and Ameeta, 2001). Oxidative stress has been implicated in the pathogenesis of drug-induced renal damage, and reactive oxygen species (ROS) have been suggested to be the central key in the mechanisms that lead to tubular necrosis (Lopez-Novoa et al., 2011). Diethylnitrosamine (DEN), a hepatocarcinogen, is produced from the metabolism of some drugs and also found in processed meats, tobacco smoke, soybean, cheese and wide variety of foods (Verna et al., 1996). During metabolism, DEN has been reported to induce oxidative stress, leading to cytotoxicity, mutagenicity and carcinogenicity (Pradeep et al., 2007; Farombi et al., 2009). Pradeep et al., (2010) stated that DEN is biotransformed by cytochrome P450

* Corresponding Author Ayman M Mahmoud, Physiology Division, Zoology Department, Faculty of Science, Beni-Suef University, Beni-Suef, Egypt. Email:ayman.mahmoud@science.bsu.edu.eg dependent monooxidase systems and its metabolic activation is responsible for the onset of the toxic effects. Due to the key role of oxidative stress in DEN-induced toxicity, the use of antioxidants could offer protection against its deleterious effects.

Medicinal plants play a central role in managing human diseases and numerous drugs have been developed from natural sources (Balunas and Kinghorn, 2005). Ruta graveolens L. (Family: Rutaceae), commonly known as rue or sadab, is an ancient medicinal plant and currently used for treatment of multiple disorders, including eye problems, aching pain, dermatitis and rheumatism (Miguel, 2003). In addition, $R$. graveolens has been extensively used in treatment of vitiligo, psoriasis, leucoderma, multiple sclerosis, cutaneous lymphomas, and recently reported to possess anticancer, anti-inflammatory, hepatoprotective and antidiabetic activity (Pathak et al., 2003; Preethi et al., 2006; Ahmed et al., 2010; Mahmoud et al., 2014). It has also been used for gastric disorders, stiff neck, dizziness and headache (Conway and Slocumb, 1979); however, its protective effects against DEN-induced nephro-toxicity were not reported. 
Phytochemical investigations of $R$. graveolens have demonstrated the presence of fats, oils, flavonoids, furoquinolone, alkaloids, terpenoids, glycosides, essential oils, steriods, sterols, tannins, coumarins, saponin, cardioglycosides, carbohydrates, amino acids, protein and others (Inna et al., 2004; Khare, 2007; Ahmed et al., 2010; Rajeshwari et al., 2011).Flavonoids are nonnutritive dietary components widely distributed in plants (Mahmoud, 2012) and possess a wide range of biological effects (Zhao et al., 2007). The flavonoid rutin is extensively found in many plants and it is considered the active constituent of $R$. graveolens. It is also called rutoside, quercitin-3-rutinoside and sophorin. This flavonoid has been reported to exert a broad range of biological activities, including antimicrobial (Arima et al., 2002), antiviral (Middleton et al., 2000), neuroprotective (Gupta et al., 2003), anti-inflammatory (Mahmoud and Soliman, 2013), hepatoprotective (Mahmoud, 2012) and antidiabetic (Ahmed et al., 2010; Mahmoud and Soliman, 2013).

To the best of our knowledge, reports evaluating the protective effects of $R$. graveolens and its major constituent rutin against DEN-induced nephrotoxicity are scarce. Therefore, the intention of the present study was to demonstrate the efficacy of rue ethanolic extract and rutin in the modulation of oxidative stress and cell damage associated with DEN-induced nephrotoxicity in Wistar rats.

\section{MATERIALS AND METHODS}

\section{Chemicals}

Rutin, diethylnitrosamine (DEN), phenobarbital (PB), glutathione (GSH), pyrogallol, thiobarbituric acid (TBA) and 5,5'dithiobis- (2-nitrobenzoic acid) (DTNB) were purchased from Sigma (USA). All other chemicals were of analytical grade and obtained from standard commercial supplies.

\section{Collection of plant and extract preparation}

$R$. graveolens (sadab) was obtained from the Experimental Station of Medical Plants (ESMP), Faculty of Pharmacy, Cairo University, Egypt. The plant leaves were cleaned, air dried and ground with an electric grinder. The extract was prepared by maceration in $80 \%$ aqueous ethanol for $24 \mathrm{~h}$ at room temperature. After filtration, the filtrate was concentrated under vacuum in a rotary evaporator. The residue obtained was stored frozen till use.

\section{Animals and treatments}

Twenty-four male Wistar rats weighing 130-150 g, obtained from the animal house of the National Research Centre (El-Giza, Egypt) were included in the present investigation. The animals were housed in plastic well-aerated cages (6 rats/cage) at normal atmospheric temperature $\left(25 \pm 5^{\circ} \mathrm{C}\right)$ and normal $12 \mathrm{~h}$ light/dark cycle. Rats had free access to water and were supplied daily with laboratory standard diet of known composition ad libitum. All animal procedures were undertaken with the approval of Institutional Animal Ethics Committee of Beni-Suef University
(Egypt). Rats were divided to four groups $(\mathrm{N}=6)$ and were subjected to the following treatments:

Group 1 (Control): animals were injected with a single dose of saline $(0.9 \%)$ and orally administered the vehicle $1 \%$ carboxymethylcellulose (CMC)

Group 2 (DEN): animals were given a single intraperitoneal injection of DEN (200 mg/kg b.wt) (Banakar et al., 2004) and given $1 \%$ CMC by gavage daily throughout the experimental period. Two-weeks after DEN administration, rats received $0.5 \mathrm{~g} / \mathrm{L}$ Phenobarbital in drinking water (Banakar et al., 2004) for 12 weeks.

Group 3 (DEN $+R$. graveolens): DEN/PB-treated animals received $50 \mathrm{mg} / \mathrm{kg} R$. graveolens dissolved in $1 \% \mathrm{CMC}$ by gavage daily throughout the experimental period (Ratheesh and Helen, 2007).

Group 4 (DEN + Rutin): DEN/PB-treated animals received $50 \mathrm{mg} / \mathrm{kg}$ rutin by gavage daily throughout the experimental period (Mahmoud, 2012).

The doses of $R$. graveolens and rutin were balanced consistently as indicated by any change in body weight to keep up comparable dosage for every kg body weight over the entire period of study. By the end of the experiment, animals were sacrificed and blood samples were collected, left to coagulate and centrifuged at $3000 \mathrm{rpm}$ for $15 \mathrm{~min}$ to separate serum. Kidney samples were immediately excised and perfused with ice-cold saline. Frozen samples $(10 \% \mathrm{w} / \mathrm{v})$ were homogenized in chilled saline and the homogenates were centrifuged at $3000 \mathrm{rpm}$ for 10 min. The clear homogenates were collected and used for subsequent assays.

\section{Biochemical assays \\ Determination of serum creatinine and uric acid}

Serum urea, creatinine and uric acid levels were assayed using reagent kits purchased from Biosystems (Spain), following the methods of Kaplan (1984), Young (1995) and Fossati et al. (1980), respectively.

\section{Determination of oxidative stress and antioxidant system parameters}

Lipid peroxidation, assayed as malondialdehyde (MDA), was determined in kidney homogenates according to the methods of Preuss et al. (1998). Reduced glutathione (GSH) content was assayed according to the method of Beutler et al. (1963). Activities of superoxide dismutase (SOD), glutathione peroxidase (GPx) and glutathione-s-transferase (GST) were measured according to the methods of Marklund and Marklund (1964), Matkovics et al. (1998) and Mannervik and Gutenberg (1981), respectively.

\section{Histopathological study}

The kidney samples were flushed with cold saline and then fixed in $10 \%$ buffered formalin for at least $24 \mathrm{~h}$. The specimens were then dehydrated in ascending series of ethanol, cleared in xylene and embedded in paraffin wax. Blocks were prepared and $4 \mu \mathrm{m}$ thick sections were cut by a sledge microtome. 
The paraffin embedded sections were deparaffinized, washed and stained with hematoxylin and eosin (H\&E). The stained slides were examined under light microscope.

\section{Statistical analysis}

Statistical analysis was performed using GraphPad Prism 5 software (GraphPad Software, San Diego, CA, USA). Results were expressed as mean \pm standard error (SEM) and all statistical comparisons were made by means of the one-way ANOVA test followed by Tukey's test post hoc analysis. A P value $<0.05$ was considered significant.

\section{RESULTS}

DEN-administration resulted in marked impairment of kidney function as demonstrated by the significant increase in serum urea $(\mathrm{P}<0.01)$, creatinine $(\mathrm{P}<0.001)$ and uric acid $(\mathrm{P}<0.001)$ levels (Table 1). Oral administration of either $R$. graveolens or rutin to DEN-treated rats significantly decreased the elevated levels of serum urea, creatinine and uric acid when compared with the DEN control group. However non-significant differences exist, rutin seemed to be more effective in ameliorating serum urea, creatinine and uric acid than $R$. graveolens.

Table 1: Serum urea, creatinine and uric acid levels in control, DEN and DEN rats treated with $R$. graveolens and rutin.

\begin{tabular}{cccc}
\hline & $\begin{array}{c}\text { Urea } \\
(\mathbf{m g} / \mathbf{d l})\end{array}$ & $\begin{array}{c}\text { Creatinine } \\
(\mathbf{m g} / \mathbf{d l})\end{array}$ & $\begin{array}{c}\text { Uric acid } \\
(\mathbf{m g} / \mathbf{d l})\end{array}$ \\
\hline Control & $29.05 \pm 3.39$ & $0.59 \pm 0.108$ & $0.45 \pm 0.027$ \\
DEN & $71.53 \pm 9.28^{* *}$ & $1.062 \pm 0.056^{* * *}$ & $1.168 \pm 0.149^{* * *}$ \\
DEN $+R$. graveolens & $31.41 \pm 5.59^{\#}$ & $0.747 \pm 0.027^{\#}$ & $0.601 \pm 0.045^{\# \#}$ \\
DEN + Rutin & $38.21 \pm 1.91^{\#}$ & $0.73 \pm 0.044^{\#}$ & $0.515 \pm 0.081^{\# \#}$ \\
\hline Data are expressed as $\mathrm{M} \pm$ SEM. ${ }^{* *} \mathrm{P}<0.01$ and ${ }^{* * * *} \mathrm{P}<0.001$ & vs control, and \\
${ }^{\#} \mathrm{P}<0.05{ }^{\# \#} \mathrm{P}<0.01$ and ${ }^{\# \# \#} \mathrm{P}<0.001$ vs $\mathrm{DEN}$. &
\end{tabular}

Histopatholgical examination of the kidney sections of control rats revealed normal histological structure (Fig. 1A). On the other hand, DEN administration produced histological changes and several lesions including dysplastic renal tubules with karyomegalic nuclei, atrophy of glomerular tuft and inflammatory cells infiltration (Fig. 1B). The histopathological alterations are summarized in Table 2. Treatment of the DEN-administered rats with $R$. graveolens extract (Fig. 1C) as well as rutin (Fig. 1D) produced marked improvement in the kidney histological structure and prevented the DEN-induced alterations.

Table 2: Histopathological lesions in kidney sections of control, DEN and DEN rats treated with $R$. graveolens and rutin.

\begin{tabular}{lccc}
\hline \multicolumn{1}{c}{ Histopathological lesions } & DEN & $\begin{array}{c}\text { DEN + R. } \\
\text { graveolens }\end{array}$ & $\begin{array}{c}\text { DEN + } \\
\text { Rutin }\end{array}$ \\
\hline Adenoma & +++ & - & - \\
Karyomegalic nuclei & ++ & - & - \\
Atrophy of glomerular tuft & ++ & - & - \\
Inflammatory cells infiltration & ++ & - & - \\
Protein cast in the lumen of renal tubules & ++ & - & - \\
Vacuolation of renal tubules & - & - & - \\
\hline
\end{tabular}

DEN-administered rats exhibited significant $(\mathrm{P}<0.001)$ elevation in the renal lipid peroxidation marker MDA when compared with the control group of rats, as represented in Figure 2. Oral supplementation of either $R$. graveolens or rutin to the DEN-treated rats significantly $(\mathrm{P}<0.001)$ decreased MDA content.

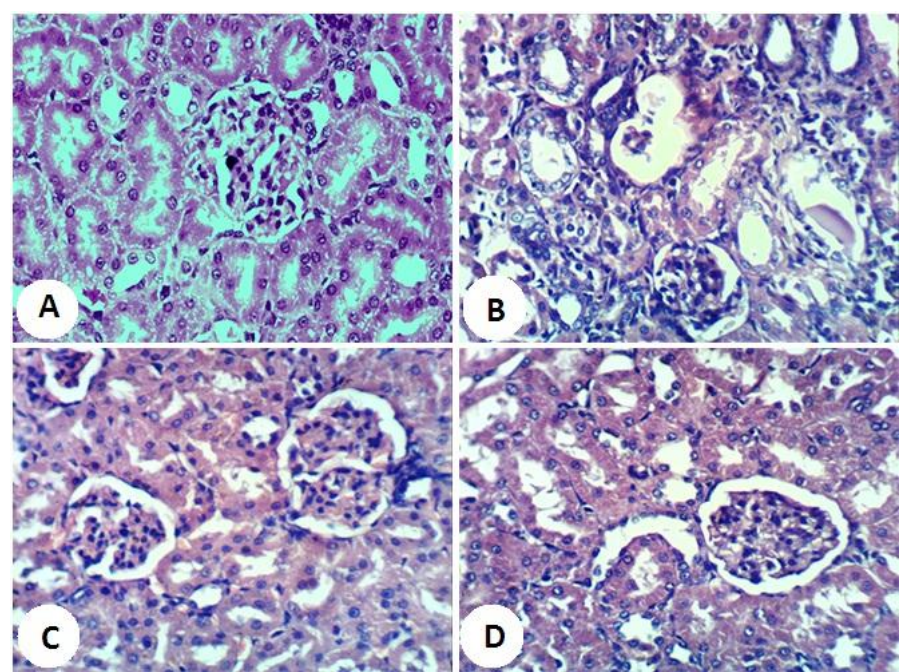

Fig. 1: Photomicrographs of H\&E stained kidney sections of control (A) showing normal histological structure, DEN (B) showing several lesions including dysplastic renal tubules with karyomegalic nuclei, atrophy of glomerular tuft and inflammatory cells infiltration, DEN $+R$. graveolens $(\mathrm{C})$ and DEN + Rutin (D) showing nearly normal renal tubules (t) and renal corpuscles. (X400).
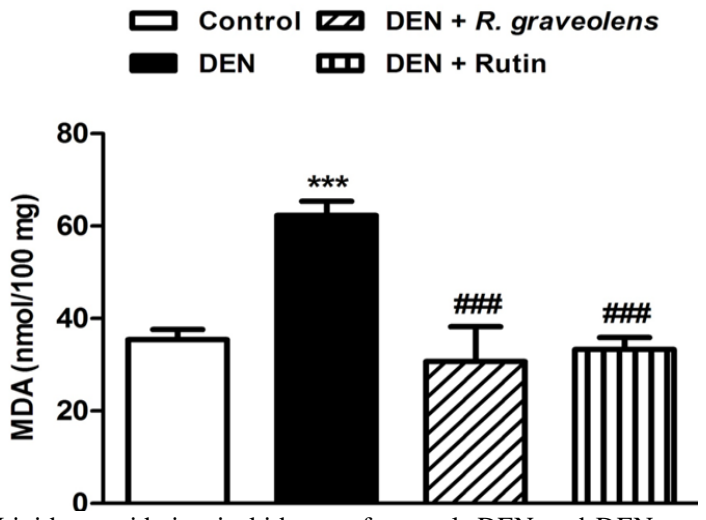

Fig. 2: Lipid peroxidation in kidneys of control, DEN and DEN rats treated with $R$. graveolens and rutin. Data are expressed as $\mathrm{M} \pm$ SEM. ${ }^{* * *} \mathrm{P}<0.001$ vs control and ${ }^{\# \# \#} \mathrm{P}<0.001$ vs DEN.

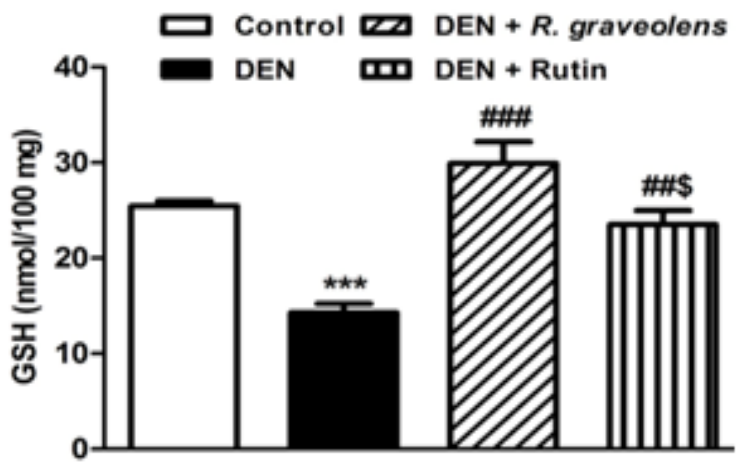

Fig. 3: Reduced glutathione (GSH) content in kidneys of control, DEN and DEN rats treated with $R$. graveolens and rutin. Data are expressed as $\mathrm{M} \pm$ SEM. ${ }^{* * *} \mathrm{P}<0.001$ vs control, ${ }^{\# \#} \mathrm{P}<0.01$ and ${ }^{\# \# \#} \mathrm{P}<0.001$ vs DEN, and ${ }^{\$} \mathrm{P}<0.05$ vs $\mathrm{DEN}+R$. graveolens. 
In contrast, GSH content showed significant $(\mathrm{P}<0.001)$ decrease in renal homogenate of DEN-administered rats when compared with the corresponding control group (Figure 3). Supplementation with either $R$. graveolens or rutin significantly $(\mathrm{P}<0.001)$ ameliorated renal GSH content with more potent effect offered by $R$. graveolens.

Similarly, DEN-administered rats exhibited significant decline in the activity of SOD $(\mathrm{P}<0.05)$, GPx $(\mathrm{P}<0.001)$ and GST $(\mathrm{P}<0.001)$ when compared with the normal control rats. $R$. graveolens markedly ameliorated the activity of SOD $(\mathrm{P}<0.001)$, GPx $(\mathrm{P}<0.01)$ and GST $(\mathrm{P}<0.001)$. Rutin as well produced significant amelioration in the activity of SOD $(\mathrm{P}<0.01)$, GPX $(\mathrm{P}<0.05)$ and GST $(\mathrm{P}<0.05)$ as represented in Figures 4, 5 and 6 , respectively.

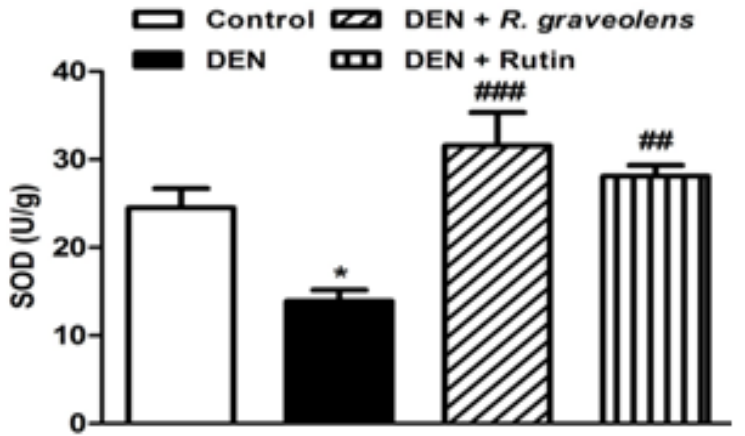

Fig. 4: Superoxide dismutase (SOD) activity in kidneys of control, DEN and DEN rats treated with $R$. graveolens and rutin. Data are expressed as $\mathrm{M} \pm$ SEM. ${ }^{*} \mathrm{P}<0.05$ vs control, and ${ }^{\# \#} \mathrm{P}<0.01$ and $^{\# \# \#} \mathrm{P}<0.001$ vs DEN.

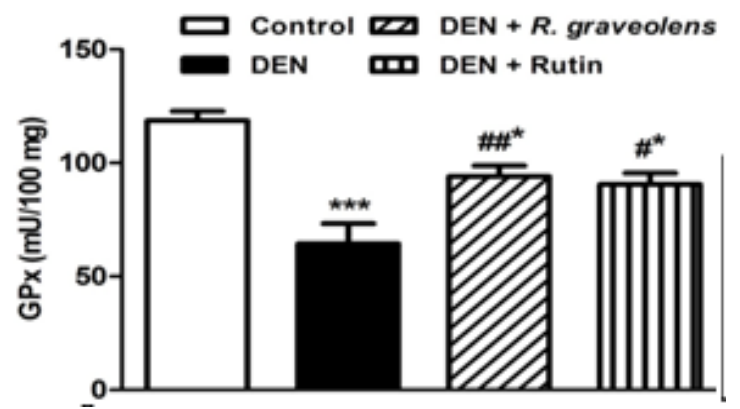

Fig. 5: Glutathione peroxidase (GPx) activity in kidneys of control, DEN and DEN rats treated with $R$. graveolens and rutin. Data are expressed as $\mathrm{M} \pm$ SEM. ${ }^{* * *} \mathrm{P}<0.001$ vs control, and ${ }^{\#} \mathrm{P}<0.05$ and ${ }^{\# \#} \mathrm{P}<0.01$ vs DEN.

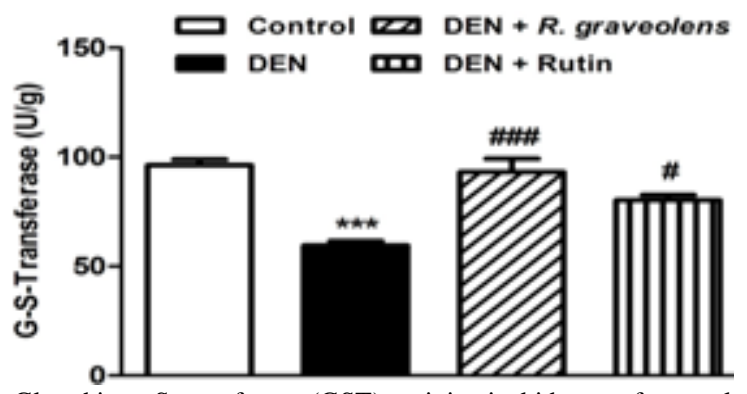

Fig. 6: Glutathione-S-transferase (GST) activity in kidneys of control, DEN and DEN rats treated with $R$. graveolens and rutin. Data are expressed as $\mathrm{M} \pm \mathrm{SEM} .{ }^{* * *} \mathrm{P}<0.001$ vs control, and ${ }^{\#} \mathrm{P}<0.05$ and ${ }^{\# \# \#} \mathrm{P}<0.001 \mathrm{v}$ sDEN.

\section{DISCUSSION}

DEN was suggested to be important environmental carcinogen, leading to generation of ROS and eventually resulting in oxidative stress and cellular injury (Bartech et al., 1989). Being metabolized by cytochrome P450, DEN generates highly reactive free radicals and, initiates lipid peroxidation of the cell and endoplasmic reticulum membranes (Archer, 1989; Vitaglione et al., 2004). These resulting radicals have the ability to cause oxidative damage in DNA, proteins and lipids (Vitaglione et al., 2004). Therefore, the use of antioxidants could protect against DEN-induced oxidative stress and nephrotoxicity. We designed the current study to test the hypothesis that $R$. graveolens and its main constituent rutin, through their antioxidant efficacy, could protect against DEN-induced renal damage.

The present study showed that the administration of DEN has induced renal damage and this was evident by the increased levels of serum toxicity markers like urea, creatinine and uric acid of DEN-induced rats. It has been reported that serum creatinine level relates to glomerular function and its rise is an indicator of renal failure (Adejuwon and Adokiye, 2008; Nenad et al., 2008). These findings are in agreement with the studies of Rezaie et al. (2013) and Pashmforoosh et al. (2015) who demonstrated increased serum urea and creatinine levels in DEN-administered rats. Also, Lily and James (2008) stated that the elevation of uric acid in blood (hyperuricemia) is considered a sensitive marker of inflammation taking place at various sites of the body. In addition, renal injury induced by DEN was confirmed by the observed histological alterations, including adenoma, dysplastic renal tubules with karyomegalic nuclei, atrophy of glomerular tuft and inflammatory cells infiltration. Concurrent administration of either $R$. graveolens or rutin markedly decreased serum levels of urea, creatinine and uric acid, and potentially prevented the DENinduced histological alterations in the kidney. The nephronprotective effects of $R$. graveolens and rutin have been demonstrated in few studies. Shaheen (2013) reported the renoprotective effects of rutin in DEN-induced animals. We recently reported that both $R$. graveolens and rutin were able to decrease serum urea, creatinine and uric acid levels in ammonium chloride-induced hyperammonemic rats (Mahmoud, 2012; Mahmoud et al., 2014).

The abundance of long chain polyunsaturated fatty acids in the composition of renal lipids makes the kidney vulnerable to damage caused by ROS (Ozbek, 2012). The metabolism of nitrosamines has been suggested to generate ROS (Kaul et al., 1993). The produced ROS induce cellular injury, DNA fragmentation, protein damage and lipid peroxidation, and alter the antioxidant defense system (Bansal et al., 2005; Mittal et al., 2006; Nencini et al., 2007). In our study it was noticed that the homogenate of kidney of the DEN-induced rats exhibited a significant increase in levels of MDA, indicating a serious damage to kidney tissue. The elevated MDA levels could be explained by the study of Nakae et al. (1997) who reported that DEN intercalate with membrane lipids and form free radicals which increase lipid 
peroxidation. Subsequently, the membrane function is altered by decreasing its fluidity and changing the activity of its bounding enzymes and their receptors (Arulselvan and Subramanian, 2007). Daily treatment with rutin and $R$. graveolens markedly ameliorated the elevated levels of MDA suggesting evidence that either treatment possess a potent free radical scavenging activity. We have confirmed the radical scavenging activity of rutin and $R$. graveolens in hyperammonemic (Mahmoud, 2012; Mahmoud et al., 2014) and diabetic rats (Mahmoud and Soliman, 2013).

In contrast, DEN-administered rats exhibited significant decrease in renal GSH content. GSH is a potent antioxidant which protects the cellular constituents against the damage induced by the free radicals (Franco et al., 2007), through the formation of Sconjugates with products of lipid peroxidation (Laurent et al., 2000). Therefore, GSH decline leads to lowered cellular defense against free radical induced cellular injury resulting in cell death (Srivastava and Shivanandappa, 2010). Similarly, reduction in the activity of the antioxidant enzymes SOD, GPx and GST was observed in kidneys of DEN-administered rats. SOD and GPx play a significant role in maintaining the body's defense mechanism against the deleterious effects of ROS (Chandra et al. 2000; Swamy et al., 2010; Wei et al. 2011), and GST is an extra key detoxifying enzyme (Mate's et al., 2010). The noticed reduction in the activity of the antioxidant enzymes may be attributed directly to the excessive production of ROS in DEN-induced rats. On the other hand, oral administration of either $R$. graveolens or rutin markedly alleviated renal GSH content as well as activity of the antioxidant enzymes. Therefore, we assume that the nephroprotective mechanism of $R$. graveolens and rutin against DEN-induced oxidative stress is partially mediated by preventing GSH decline and potentiation of the enzymatic antioxidant defenses. These findings provide an evidence on the antioxidant and radical scavenging activity of $R$. graveolens and its flavonoid rutin documented in our previous studies (Ahmed et al., 2010; Mahmoud, 2012; Mahmoud and Soliman, 2013; Mahmoud et al., 2014).

\section{CONCLUSION}

The present findings indicate that $R$. graveolens and its active phenolic component rutin exert protection against DENinduced renal toxicity in albino rats. Their renoprotective effects could be attributed to the inhibition of lipid peroxidative system through prevention of GSH decline and enhancement of the enzymatic antioxidants.

\section{REFERENCES}

Adejuwon AA, Adokiye SB. Protective effect of the aqueous leaf and seed extract of Phyllanthus amarus on gentamicin and acetaminophen-induced nephrotoxic rats. J Ethnopharmacol, 2008; 118: 318-323.

Ahmed OM, Moneim AA, Yazid IA, Mahmoud AM. Antihyperglycemic, antihyperlipidemic and antioxidant effects and the probable mechanisms of action of Ruta graveolens infusion and rutin in nicotinamide-streptozocin induced diabetic rats. Diabetol Croat, 2010; 39: $15-35$.

Archer MC. Mechanisms of action of N-nitroso compounds. Cancer Surv, 1989; 8: 241-250.

Arima H, Ashida H, Danno G. Rutin-enhanced antibacterial activities of flavonoids against Bacillus cereus and Salmonella enteritidis. Biosci Biotechnol Biochem, 2002; 66: 1009-1014.

Arulselvan P, Subramanian SP. Beneficial effects of Murraya koenigii leaves on antioxidant defense system and ultrastructural changes of pancreatic $\beta$-cells in experimental diabetes in rats. Chem Biol Interact, 2007; 165: 155-164.

Balunas MJ, Kinghorn AD. Drug discovery from medicinal plants. Life Sci, 2005; 78:431-441.

Banakar MC, Paramasivan SK, Chattopadhyay MB, Datta S, Chakraborty P, Chatterjee M, Kannan K, Thygarajan E.1alpha, 25dihydroxyvitamin D3 prevents DNA damage and restores antioxidant enzymes in rat hepatocarcinogenesis induced by diethylnitrosamine and promoted by phenobarbital. World J Gastroenterol, 2004; 10:1268-1275.

Bansal AK, Bansal M, Soni G, Bhatnagar D. Protective role of Vitamin $\mathrm{E}$ pre-treatment on $\mathrm{N}$-nitrosodiethylamine induced oxidative stress in rat liver. Chem Biol Interact, 2005; 156: 101-111.

Bartech H, Heathen E, Melville C. Carcinogenic nitrosamines: Free radical aspects of their action. Free Radic Boil Med, 1989; 7: 637644.

Beutler E, Duron O, Kelly BM. Improved method for the determination of blood glutathione. J Lab Clin Mid, 1963;61:882-888.

Chandra J, Samali A, Orrenius, S. Triggering and modulation of apoptosis by oxidative stress. Free RadicBiol Med, 2000; 29:323-333.

Conway GA, Slocumb JC. Plants used as abortifacients and emmenagogues by Spanish New Mexicans. J Ethnopharmacol, 1979; 1: 241-261

Farombi EO, Shrotriya S, Surh YJ. Kolaviron inhibits dimethyl nitrosamine-induced liver injury by suppressing COX-2 and iNOS expression via NF-kappa B and AP-1. Life Sci, 2009; 84:149-155.

Fossati P, Prencipe L, Berti G. Use of 3,5-dichloro-2hydroxybenzenesulfonic acid/4-aminophenazone chromogenic system in direct enzymic assay of uric acid in serum and urine. Clin Chem, 1980; 26:227-231.

Franco R, Schonveld OJ, Papa A, Panayiotidis MI. The central role of glutathione in the pathophysiology of human diseases. Arch. Physiol. Biochem, 2007; 113: 234-258.

Gupta R, Singh M, Sharma A. Neuroprotective effect of antioxidants on ischaemia and reperfusion-induced cerebral injury. Pharmacol Res 2003; 48: 209-215.

Inna $\mathrm{K}$, Irina $\mathrm{K}$, Bernd $\mathrm{S}$. Specific accumulation and revised structures of acridone alkaloid glucosides in the tips of transformed root of Ruta graveolens. Phytochemistry, 2004; 65: 1095-1100.

Kaplan A. Urea. Kaplan A. 1984. Clin Chem The CV Mosby Co St Louis. Toronto. Princeton. 1257-60 and 437 and 418.

Kaul N, Siveski-Iliskovic N, Hill M, Slezak J, Singal PK. Free radicals and the heart. J Pharmacol Toxicol Methods, 1993;30:55-67.

Khare CP. 2007. Indian Medicinal Plants: An Illustrated Dictionary. Springer, New York, USA.

Laurent A, Perdu-Durand E, Alary J, DE Brauwer L, Cravedi JP. Metabolism of 4-hydroxynonenal, a cytotoxic product of lipid peroxidation in rat precision-cut liver slices. Toxicol Lett, 2000; 114:203214.

Lily L, James T. Serum uric acid is a marker of inflammation and a marker predicting the risk of developing CVD, stroke, renal failure and cancer. J Biomed Lab Sci, 2008; 20:1-6.

Lopez-Novoa JM, Quiros Y, Vicente L, Morales AI, LopezHernandez FJ. New insights into the mechanism of aminoglycoside nephrotoxicity: an integrative point of view. Kidney Int, 2011;79:33-45.

Mahmoud AM, Germoush MO, Soliman AS. Ruta graveolens mitigates ammonium chloride-induced hyperammonemia by modulating antioxidant status and pro-inflammatory cytokines. Life Sci J, 2014; 11: 269-275. 
Mahmoud AM, Soliman AS. Rutin attenuates hyperlipidemia and cardiac oxidative stress in diabetic rats. Egypt J Med Sci, 2013; 34 : 287-302.

Mahmoud AM. Influence of rutin on biochemical alterations in hyperammonemia in rats. Exp Toxicol Pathol, 2012; 64: 783-789.

Mannervik B, Guthenberg C. Glutathione transferase (Human placenta). Methods Enzymol, 1981; 77: 231-235.

Marklund SL, Marklund G. Involvement of the superoxide anion radical in the autoxidation of pyrogallol and a convenient assay for superoxide dismutase. Eur J Biochem ,1974; 47: 469-474.

Mate's JM, Segura JA, Alonso FJ, Ma'rquez J. Roles of dioxins and heavy metals in cancer and neurological diseases using ROS-mediated mechanisms. Free Radic Biol Med, 2010; 49:1328-1341.

Matkovics B, Szabo L, Varga IS. Determination of enzyme activities in lipid peroxidation and glutathione pathways (in Hungarian). Laboratoriumi Diagnosztika, 1998;15:248-249.

Middleton J, Kandaswami E, Theoharides C. The effects of plant flavonoids on mammalian cells: Implications for inflammation, heart disease, and cancer. Pharmacol Rev, 2000; 52: 673-751.

Miguel ES. Rue in traditional Spain: frequency and distribution of its medicinal and symbolic applications. Econ Bot, 2003; 57: 231-244.

Mittal G, Brar AP, Soni G. Impact of hypercholesterolemia on toxicity of Nnitrosodiethylamine: Biochemical and histopathological effects. Pharmacol Rep, 2006; 58:413-419.

Nakae D, Kobayashi Y, Akai H, Nabuaki A. Involvement of 8hydroxyguanine formation in the inhibition of rat liver carcinogenesis by low dose levels of N-nitrosodiethylamine. Cancer Res, 1997; 57: 12811287.

Nenad S, Dragan M, Slavimir V. Glomerular basement membrane alterations induced by gentamicin administration in rats. Exp Toxicol Pathol, 2008; 60: 69-75.

Nencini C, Giorgi G, Micheli L. Protective effect of silymarin on oxidative stress in rat brain. Phytomedicine, 2007; 14:129-135.

Ozbek E. Induction of oxidative stress in kidney. Int J Nephrol, 2012; 2012: 465-897.

Pashmforoosh M, Rezaie A, Haghi-Karamallah M, Fazlara A, Shahriari A, Najafzadeh $\mathrm{H}$. Effects of caffeine on renal toxicity induced by diethylnitrosamine. Zahedan J Res Med Sci, 2015; 17: 7-9.

Pathak S, Multani A, Banerji P, Banerji P. Ruta 6 selectively induces cell death in brain cancer cells but proliferation in normal peripheral blood lymphocytes: a novel treatment for human brain cancer. Int J Oncol, 2003; 23:975-982.

Pradeep K, Mohan CV, Gobianand K, Karthikeyan S. Silymarin modulates the oxidant-antioxidant imbalance during diethylnitrosamine induced oxidative stress in rats. Eur J Pharmacol, 2007; 560:110-116.

Pradeep K, Raj Mohan CV, Gobianand K, Karthikeyan S. Protective effect of Cassia fistula Linn. On diethylnitrosamine induced hepatocellular damage and oxidative stress in ethanol pretreated rats. Biol Res, 2010; 43:113-125.

Preethi K, Kuttan G, Kuttan R. Anti-tumour activity of Ruta graveolens extract. Asian Pac J Cancer Prev, 2006; 7: 439-443.

Preuss HG, Jarrell ST, Scheckenbach R, Lieberman S, Anderson RA. Comparative effect of chromium vanadium and Gymnemasylvestre on sugar-induced blood pressure elevation in SHR. J Am Coll Nutr, 1998;17:116-123.
Rajeshwari S, Balakrishnan A, Thenmozhi M, Venckatesh R. Preliminary phytochemical analysis of Aegle marmelos, Ruta graveolens, Opuntia dellini, Euphorbia royleana and Euphorbia antiquorum. Int J Pharm Sci Res, 2011; 2: 132-136.

Ratheesh M, Helen A. Anti-inflammatory activity of Ruta graveolens Linn on carrageenan induced paw edema in wistar male rats. Afr J Biotechnol, 2007; 6: 1209-1011.

Rezaie A, Fazlara A, Haghi-KaramolahM, Zadeh HN, Pashmforosh M. Effects of Echinacea purpurea on hepatic and renal toxicity induced by diethylnitrosamine in rats. Jundishapur J Nat Pharm Prod, 2013; 8:60-64.

Sarang J, Ameeta A. Protective effect of Bryophyllum pinnatum, Syzygium aromaticum and Ocimum sanctum based polyherbal formulation on gentamicin-induced nephrotoxicity. Mol Clin. Pharmacol, 2001; 2: 55-59.

Shaheen NEM. Oxidative stress of diethylnitrosamine on the functions of kidney in male rats and effective role of rutin and/or selenium. J Appl Sci Res, 2013;9: 6684-6691.

Srivastava A, Shivanandappa T. Hepatoprotective effect of the root extract of Decalepishamiltonii against carbon tetrachloride-induced oxidative stress in rats. Food Chem, 2010; 118:411-417.

Swamy AHMV, Kulkarni RV, Thippeswamy AHM, Koti BC, Gore A. Evaluation of hepatoprotective activity of Cissus quadrangularis stem extract against isoniaized -induced liver damage in rats. Indian $\mathrm{J}$ Pharmacol, 2010; 42:397-400.

Verna L, Whysner J, Williams GM. N-nitrosodiethylamine mechanistic data and risk assessment: bioactivation, DNA-adduct formation, mutagenicity, and tumor initiation. Pharmacol Ther, 1996; 71: $57-81$.

Vitaglione P, Morisco F, Caporaso N, Fogliano V.Dietary antioxidant compounds and liver health. Crit Rev Food Sic Nutr, 2004; 44 575-586.

Wei XJ, Hu TJ, Chen JR, Wei YY. Inhibitory effect of carboxymethylpachymaran on cyclophosphamide-induced oxidative stress in mice. Int J Biol Macromol, 2011; 49: 801-805. AACC Press.

Young DS.1995. Effects of drugs on Clinical Lab. Tests, $4^{\text {th }}$ ed

Zhao M, Yang B, Wang J, Liu Y, Yu L, Jiang Y. Immunomodulatory and anticancer activities of flavonoids extracted from litchi (Litchi chinensisSonn) pericarp. Int Immunopharmacol, 2007; 7: 162-166.

\section{How to cite this article:}

Ayman M Mahmoud, Rasha R Ahmed, Hanan A Soliman, Marwa Salah. Ruta graveolens and its active constituent rutin protect against diethylnitrosamine-induced nephrotoxicity through modulation of oxidative stress. J App Pharm Sci, 2015; 5 (10): 016-021. 